\title{
The Assessment of Tp-e Interval and Tp-e/QT Ratio in Patients With Systemic Sclerosis
}

\author{
Çağrı YAYLA, ${ }^{1}$ Müçteba Enes YAYLA, ${ }^{2}$ Kadriye GAYRETLİ YAYLA, ${ }^{3}$ \\ Ufuk İLGEN, ${ }^{2}$ Mehmet Kadri AKBOĞA, ${ }^{1}$ Nurşen DÜZGÜN ${ }^{4}$ \\ ${ }^{1}$ Department of Cardiology, Türkiye Yüksek İhtisas Training and Research Hospital, Ankara, Turkey \\ ${ }^{2}$ Department of Internal Medicine, Medical Faculty of Ankara University, Ankara, Turkey \\ ${ }^{3}$ Department of Cardiology, Dışkapı Yıldırım Beyazıt Training and Research Hospital, Ankara, Turkey \\ ${ }^{4}$ Department of Rheumatology, Medical Faculty of Ankara University, Ankara, Turkey
}

\begin{abstract}
Objectives: This study aims to investigate ventricular repolarization using T-peak to T-end (Tp-e) intervals and Tp-e/QT ratios in patients with systemic sclerosis (SSc).

Patients and methods: Totally 65 patients ( 8 males, 57 females; mean age 49.8 years; range 20 to 77 years) with SSc and 63 control subjects ( 8 males, 55 females; mean age 49.3 years; range 20 to 77 years) were enrolled. Tp-e intervals, Tp-e/QT, and Tp-e/corrected QT (QTc) ratios were measured from the 12-lead electrocardiogram.

Results: Tp-e intervals, QT intervals, QTc intervals, Tp-e/QT, and Tp-e/QTc ratios were significantly higher in patients with SSc than control subjects (all $\mathrm{p}$ <.01). There was no difference between patients with diffuse and limited cutaneous SSc in terms of electrocardiogram and echocardiographic findings. Correlation analysis revealed no correlation between Tp-e intervals, Tp-e/QT, and Tp-e/QTc ratios with disease duration and anti-Sjögren's syndrome antigen A antibody levels in patients with SSC (all $\mathrm{p}>0.05$ ).

Conclusion: Our study showed that Tp-e intervals, Tp-e/QT, and Tp-e/QTc ratios were increased in patients with SSc than control subjects. The increased frequency of ventricular arrhythmias can be clarified by increased indexes of ventricular repolarization parameters in patients with SSc. Keywords: Systemic sclerosis; Tp-e interval; Tp-e/QT ratio.
\end{abstract}

Systemic sclerosis (SSc) is a systemic connective tissue disease characterized by fibrosis of the skin and visceral organs, such as kidneys, lungs, and heart. Varied cardiovascular complications may appear in SSc, most commonly dysrhythmias and pulmonary hypertension. ${ }^{1-3}$ Cardiovascular involvement has been demonstrated to be one of the major causes of mortality in SSc and may occur in up to $70 \%$ of patients according to autopsy reports. ${ }^{4,5}$ The major causes of cardiovascular death in patients with SSc are refractory heart failure and dysrhythmias. ${ }^{6}$

Ventricular repolarization may be defined using QT interval, QT dispersion, and T wave measurements. Prolonged QT interval and increased QT dispersion have been shown in patients with $\mathrm{SSc}^{7}$ In recent studies, the Tp-e interval, the interval between the peak and the end of the $\mathrm{T}$ wave, has been specified as an index of total dispersion of repolarization..$^{8,9}$ Prolonged Tp-e interval may predict ventricular arrhythmias and mortality. ${ }^{10-12}$ Thus, Tp-e/QT ratio has been proposed to be a better marker of ventricular repolarization. ${ }^{13,14}$

To our knowledge, no trial has evaluated the Tp-e interval and Tp-e/QT ratio as markers of ventricular arrhythmogenesis in patients with SSc. Therefore, in this study, we aimed to investigate

Received: September 01, 2015 Accepted: November 26, 2015 Published online: January 27, 2016

Correspondence: Çağrı Yayla, MD. Türkiye Yüksek İhtisas Eğitim ve Araştırma Hastanesi Kardiyoloji Kliniği, 06230 Sıhhiye, Ankara, Turkey.

Tel: +90 533 - 6449643 e-mail: cagriyayla@gmail.com

O2016 Turkish League Against Rheumatism. All rights reserved. 
ventricular repolarization using Tp-e intervals and $\mathrm{Tp}-\mathrm{e} / \mathrm{QT}$ ratios in patients with SSc.

\section{PATIENTS AND METHODS}

Between January 2014 and May 2015, the study included 65 consecutive patients $(8$ males, 57 females; mean age 49.8 years; range 20 to 77 years) with SSc and 63 age and sex similar control subjects (8 males, 55 females; mean age 49.3 years; range 20 to 77 years). All patients met American Rheumatism Association's preliminary criteria for diagnosis of definite scleroderma and 2013 American College of Rheumatology/European League Against Rheumatism Classification criteria for SSc. ${ }^{15,16}$ Patients were classified as having diffuse or limited cutaneous SSc according to LeRoy Classification criteria. ${ }^{17}$ Patients with SSc were screened in terms of disease duration (defined as interval between date of diagnosis and inclusion into study) and Raynaud's phenomenon. All patients were examined to be in sinus rhythm and were asymptomatic in terms of cardiac symptoms. Patients and control subjects with diabetes mellitus, hypertension, valvular heart disease, coronary artery disease, wall motion abnormalities with left ventricular ejection fraction below 50\%, severe pulmonary disease, malignancy, kidney/hepatic failure, incomplete/ complete bundle branch block, atrial fibrillation, and paced rhythm were excluded. Baseline demographic and clinical characteristics were noted. Written informed consent was obtained from each patient. The study was in compliance with the principles outlined in the Declaration of Helsinki and approved by the Local Ethics Committee.

Echocardiographic assessment was performed by using a Vivid 7 dimension cardiovascular ultrasound system (VingmedGeneral Electric, Horten, Norway) with a 3.5 $\mathrm{MHz}$ transducer. Echocardiographic examination was performed in the left lateral decubitus position. Parasternal long- and short-axis views and apical views were used as standard imaging windows. Left atrial diameter, end systolic and end diastolic dimensions were measured from parasternal long-axis view. Ejection fraction was calculated by using modified Simpson method. All echocardiographic examinations were performed by an experienced cardiologist.

The 12-lead electrocardiogram (ECG) was recorded at a paper speed of $50 \mathrm{~mm} / \mathrm{second}$ (Hewlett Packard, Page-writer, USA) in the supine position. ECGs were performed while the patient was at rest and at 8:00-10:00 AM in the morning. All of the ECGs were scanned and transferred to a personal computer to decrease the error measurements, and then used for $\mathrm{x} 400 \%$ magnification by Adobe Photoshop software. ECG measurements of QT and Tp-e intervals were performed by two cardiologists who were blinded to the patient data. Subjects with $U$ waves on their ECGs were excluded from the study. A mean value of three readings was calculated for each lead. The QT interval was measured from the beginning of the QRS complex to the end of the $\mathrm{T}$ wave and corrected for heart rate using the Bazett's formula: cQT = $\mathrm{QT} \sqrt{ }$ (R-R interval). The Tp-e interval was defined as the interval from the peak of $\mathrm{T}$ wave to the end of $\mathrm{T}$ wave. Measurements of the Tp-e interval were performed from precordial leads. ${ }^{10}$ The Tp-e/QT ratio was calculated from these measurements. Interobserver and intraobserver coefficients of variation were $2.4 \%$ and $2.8 \%$, respectively.

Peripheral venous blood samples were drawn from the antecubital vein after 12-hour of fasting in the morning. Blood samples were taken into standardized tubes containing dipotassium ethylenedinitrilotetraacetic acid for complete blood count. Coulter Counter LH Series (Beckman coulter Inc., Hialeah, Florida) was used for complete blood count. Plasma levels of triglyceride, high-density lipoprotein cholesterol, low-density lipoprotein cholesterol, glucose, and creatinine were evaluated using an automated chemistry analyzer (Aeroset, Abbott, USA) with commercially available kits (Abbott, USA). Antinuclear antibodies were analyzed by immunofluorescence (Immunoconcepts, Sacramento, CA, USA). Anticentromere antibodies, anti-topoisomerase I antibodies and anti-Sjögren's syndrome antigen $\mathrm{A}$ and $\mathrm{B}$ were analyzed by the multiplex immunoassay BioPlex 2200 ANA screen system (Bio-Rad, Hercules, CA, USA). 


\section{Statistical analysis}

For statistical analysis, IBM SPSS version 20.0 Statistical Package Program for Windows (IBM Corporation, Armonk, NY, USA) was used. Kolmogorov-Smirnov test was used to test normality of distribution. Quantitative variables with a normal distribution were specified as the mean \pm standard deviation. Categorical variables were shown as number and percentage values. Differences between groups were evaluated by using Student's t test. Categorical variables were compared with Chi-square test. Pearson correlation analysis was performed to examine the relationship between Tp-e interval, Tp-e/QT ratio and $\mathrm{Tp}-\mathrm{e} / \mathrm{QTc}$, and other variations. A $\mathrm{p}$ value of $<0.05$ was accepted as statistically significant.

\section{RESULTS}

Baseline clinical characteristics and laboratory parameters of the study groups were listed in Table 1. There were 12 diffuse and 53 limited cutaneous SSc patients. There was no statistically significant difference between groups in terms of age, sex, and basal laboratory findings (all p>0.05), except for high-density lipoprotein cholesterol level which was significantly lower in patients with SSc than control subjects $(p=0.017)$. Mean disease duration of patients was $8.1 \pm 7.5$ years.

The ECG and echocardiographic findings were presented in Table 2. There was no difference between the two groups in terms of left ventricular ejection fraction $(p=0.108)$. Tp-e intervals, QT intervals, QTc intervals, Tp-e/QT ratios, and Tp-e/QTc ratios were significantly higher in patients with SSc than control subjects (all $p<0.01$ ). Besides, there was no difference between patients with diffuse and limited cutaneous SSc in terms of ECG and echocardiographic findings (Table 3). In correlation analysis, there were no correlations between Tp-e intervals, Tp-e/QT, and Tp-e/QTc ratios with disease duration and anti-Sjögren's syndrome antigen A antibody levels in patients with SSc ( $>00.05)$.

\section{DISCUSSION}

In this study, we demonstrated that Tp-e intervals, $\mathrm{Tp}-\mathrm{e} / \mathrm{QT}$, and Tp-e/QTc ratios were prolonged in patients with SSc as compared to healthy subjects. To the best of our knowledge, this study was the first clinical trial focusing on the relationship between Tp-e interval, Tp-e/QT, Tp-e/QTc ratios, and SSc.

Table 1. Baseline characteristics and laboratory parameters of study population

\begin{tabular}{|c|c|c|c|c|c|c|c|}
\hline \multirow[t]{2}{*}{ Parameters } & \multicolumn{3}{|c|}{ Systemic sclerosis patients $(\mathrm{n}=65)$} & \multicolumn{3}{|c|}{ Control subjects $(n=63)$} & \multirow[b]{2}{*}{$p$} \\
\hline & $\mathrm{n}$ & $\%$ & Mean \pm SD & $\mathrm{n}$ & $\%$ & Mean \pm SD & \\
\hline Age (years) & & & $49.8 \pm 13.2$ & & & $49.3 \pm 10.5$ & 0.832 \\
\hline Female & & 87.6 & & & 87.3 & & 0.947 \\
\hline Smoking & & 3.1 & & & 4.7 & & 0.389 \\
\hline Weight (kg) & & & $65.0 \pm 15.4$ & & & $67.6 \pm 9.5$ & 0.469 \\
\hline Height $(\mathrm{cm})$ & & & $162.9 \pm 7.8$ & & & $163.8 \pm 6.3$ & 0.634 \\
\hline Body mass index & & & $24.4 \pm 5.2$ & & & $25.3 \pm 4.3$ & 0.464 \\
\hline Hemoglobin (g/dL) & & & $12.7 \pm 1.3$ & & & $13.1 \pm 1.0$ & 0.159 \\
\hline Creatinine (mg/dL) & & & $0.7 \pm 0.2$ & & & $0.8 \pm 0.1$ & 0.065 \\
\hline Glucose $(\mathrm{mg} / \mathrm{dL})$ & & & $87.1 \pm 16.9$ & & & $92.4 \pm 12.0$ & 0.076 \\
\hline Total-cholesterol (mg/dL) & & & $176.8 \pm 37.8$ & & & $189.8 \pm 42.7$ & 0.115 \\
\hline HDL-cholesterol (mg/dL) & & & $48.4 \pm 15.2$ & & & $54.8 \pm 10.7$ & 0.017 \\
\hline LDL-cholesterol (mg/dL) & & & $103.8 \pm 29.6$ & & & $109.3 \pm 35.7$ & 0.406 \\
\hline Triglyceride (mg/dL) & & & $119.8 \pm 47.0$ & & & $129.4 \pm 76.0$ & 0.461 \\
\hline Diffuse/limited & $12 / 53$ & & & - & & & - \\
\hline Raynaud's phenomenon (+/-) & $60 / 5$ & & & - & & & - \\
\hline Anti-centromere antibodies (+/-) & $24 / 41$ & & & - & & & - \\
\hline Anti-Ro/SSA antibodies (+/-) & $15 / 50$ & & & - & & & - \\
\hline Anti-La/SSB antibodies (+/-) & $4 / 61$ & & & - & & & - \\
\hline Anti-Scl-70 antibodies (+/-) & $19 / 46$ & & & - & & & - \\
\hline Antinuclear antibodies (+/-) & $62 / 3$ & & & - & & & - \\
\hline Disease duration (years) & & & $8.1 \pm 7.5$ & & & - & - \\
\hline
\end{tabular}


Table 2. Electrocardiographic and echocardiographic characteristics of study population

\begin{tabular}{|c|c|c|c|}
\hline \multirow[t]{2}{*}{ Parameters } & Systemic sclerosis patients $(n=65)$ & Control subjects $(n=63)$ & $p$ \\
\hline & Mean \pm SD & Mean \pm SD & \\
\hline Heart rate (bpm) & $77.1 \pm 15.2$ & $75.3 \pm 11.4$ & 0.503 \\
\hline Tp-e interval (ms) & $70.0 \pm 10.8$ & $53.2 \pm 9.4$ & $<0.001$ \\
\hline QT interval (ms) & $367.1 \pm 35.6$ & $347.7 \pm 26.0$ & 0.002 \\
\hline QTc interval (ms) & $410.8 \pm 30.2$ & $386.9 \pm 33.8$ & 0.001 \\
\hline $\mathrm{Tp}-\mathrm{e} / \mathrm{QT}$ ratio & $0.19 \pm 0.03$ & $0.15 \pm 0.02$ & $<0.001$ \\
\hline Tp-e/QTc ratio & $0.17 \pm 0.02$ & $0.14 \pm 0.02$ & $<0.001$ \\
\hline Left ventricular ejection fraction & $60.4 \pm 2.3$ & $61.2 \pm 2.5$ & 0.108 \\
\hline Left ventricular end diastolic diameter (mm) & $44.9 \pm 4.2$ & $45.9 \pm 3.0$ & 0.193 \\
\hline Left ventricular end sistolic diameter (mm) & $26.3 \pm 4.9$ & $28.0 \pm 2.7$ & 0.068 \\
\hline Left atrial diameter $(\mathrm{mm})$ & $34.0 \pm 6.3$ & $33.8 \pm 2.7$ & 0.918 \\
\hline
\end{tabular}

There are some studies investigating the association between SSc, coronary fibrosis, and atherosclerosis. ${ }^{18-20}$ Microvascular dysfunction and fibrosis has a major role in the pathogenesis of the SSc, especially in cardiac complications. ${ }^{2,3}$ Myocardial fibrosis is characteristic for heart involvement in SSc and observed in $50 \%$ to $70 \%$ of patients. ${ }^{4}$ Fibrosis may be a result of recurrent myocardial ischemia called myocardial Raynaud's phenomenon, similar to primary Raynaud's phenomenon. Researchers showed lesions in microvascular arteries of myocardium like in the peripheral arterioles of primary Raynaud's phenomenon to support this probability. ${ }^{21,22}$ Myocardial fibrosis plays a major role in the development of ventricular arrhythmias and makes left ventricle susceptible to by damaging electrical conduction, stimulating the development of re-entry circuits, and augmenting ventricular refractoriness and excitability of myocytes. ${ }^{23,24}$
Symptomatic cardiac involvements such as ventricular arrhythmias, significant conduction disturbances, heart failure, and moderate or severe pericardial effusion were shown in $10.1 \%$ of patients with SSc. ${ }^{25}$ Nevertheless, asymptomatic and subclinic cardiac involvement are common than estimated, prevalence being approximately $15 \%$ to $45 \% \cdot \cdot^{1-3,26}$ Kostis et al. ${ }^{6}$ showed a strong correlation between ventricular ectopic beats and total mortality and sudden death in 183 patients with SSc. Ventricular tachycardia was also found in 7\% of patients with SSc. In a study, the frequencies of ECG abnormalities such as QT prolongation and ventricular extrasystole were higher in patients with SSc. ${ }^{27}$ Sgreccia et al. ${ }^{7}$ found that QT dispersion and QT interval were increased significantly in patients with SSc. Also, Gialafos et al. ${ }^{28}$ demonstrated that abnormal spatial QRS-T angle, a marker of ventricular repolarization, was wider in patients with SSc.

Table 3. Electrocardiographic and echocardiographic characteristics of patients with systemic sclerosis

\begin{tabular}{lccc}
\hline Parameters & $\begin{array}{c}\text { Diffuse cutaneous systemic } \\
\text { sclerosis }(\mathrm{n}=12)\end{array}$ & $\begin{array}{c}\text { Limited cutaneous systemic } \\
\text { sclerosis }(\mathrm{n}=53)\end{array}$ \\
\cline { 2 - 3 } & Mean \pm SD & Mean \pm SD \\
\hline Heart rate, bpm & $73.7 \pm 5.8$ & $78.0 \pm 16.8$ \\
Tp-e interval, ms & $67.8 \pm 9.5$ & $70.6 \pm 11.2$ \\
QT interval, ms & $370.6 \pm 21.3$ & $366.2 \pm 38.9$ \\
QTc interval, ms & $409.8 \pm 19.3$ & $411.1 \pm 32.9$ \\
Tp-e/QT ratio & $0.18 \pm 0.02$ & $0.19 \pm 0.02$ \\
Tp-e/QTc ratio & $0.16 \pm 0.02$ & $0.17 \pm 0.03$ \\
Left ventricular ejection fraction & $59.5 \pm 1.3$ & $60.6 \pm 2.4$ \\
Left ventricular end diastolic diameter (mm) & $46.3 \pm 1.9$ & $44.5 \pm 4.5$ \\
Left ventricular end systolic diameter (mm) & $27.3 \pm 3.9$ & $26.1 \pm 5.2$ \\
Left atrial diameter, mm & $36.6 \pm 3.5$ & $33.2 \pm 6.8$ \\
SD: Standard deviation; Tp-e interval: T-peak to T-end interval. & & 0.346 \\
\hline
\end{tabular}


QT dispersion was described as a sign of increased dispersion of repolarization but finally lost its importance as a faulty concept. ${ }^{8,29}$ Recently, the Tp-e interval and Tp-e/QT ratio have been used as novel markers of increased dispersion of ventricular repolarization. ${ }^{13,14,30}$ Prolonged Tp-e interval was related with increased mortality in long QT syndrome, Brugada syndrome and in patients with acute ST-segment elevation myocardial infarction. ${ }^{14}$ Nevertheless, Tp-e interval is affected by alterations in heart rate and body weight. ${ }^{9}$ In recent studies, the Tp-e/QT ratio was suggested to be a more precise measure for the dispersion of ventricular repolarization than QT dispersion, QTc dispersion and Tp-e intervals, and to be independent of variations in heart rate., 9,13 The literature indicates the applicability of $\mathrm{Tp}-\mathrm{e} / \mathrm{QT}$ ratio as a potency significant index of arrhythmogenesis, under the conditions of short, normal, and long QT intervals. ${ }^{14}$ Also, several studies have demonstrated the relationship between Tp-e/QT ratio and rheumatic diseases such as rheumatoid arthritis and ankylosing spondylitis. ${ }^{31,32}$ Myocardial fibrosis is well known result of SSc. Therefore, alterations in myocardial tissue may cause heterogeneity in ventricular repolarization and this may also result in significant ventricular arrhythmias in patients with SSc. Similarly, we have found significant differences in Tp-e interval, QT interval, QTc interval, Tp-e/QT and Tp-e/QTc ratios between patients with SSc and the control group. Tp-e interval, QT interval, QTc interval, Tp-e/QT and Tp-e/QTc ratios were significantly higher in patients with SSc.

These results may contribute to the pathophysiological mechanisms of the increased prevalence of arrhythmias by specifying increased ventricular repolarization heterogeneity in patients with SSc. Increased incidence of ventricular arrhythmias may be clarified by prolonged transmural dispersion in these patients.

Our study has some limitations. First is its relatively small sample size. Second, it has a cross-sectional design and lacks follow-up of patients. Also, since we had no data on Rodnan skin scores, disease activity index, and disease severity scale, we were unable to evaluate the association between ECG findings and these indexes. Additionally, due to diurnal variation of ECG parameters in a day, 24-hour Holter ECG recording may be more valuable for evaluating dispersion of ventricular repolarization. We were unable to evaluate the relationship between ventricular arrhythmias and Tp-e interval and Tp-e/QT ratio. Therefore, long-term follow-up and large-scale prospective studies are needed to investigate the predictive value of the Tp-e interval and $\mathrm{Tp}-\mathrm{e} / \mathrm{QT}$ ratio in patients with SSc.

In conclusion, our study demonstrated that Tp-e interval, QT interval, QTc interval, Tp-e/QT and Tp-e/QTc ratios were increased in patients with SSc. Further and large-scale prospective studies are required to clarify the prognostic importance of Tp-e interval and Tp-e/QT ratio in predicting arrhythmias in patients with SSc.

\section{Declaration of conflicting interests}

The authors declared no conflicts of interest with respect to the authorship and/or publication of this article.

\section{Funding}

The authors received no financial support for the research and/or authorship of this article.

\section{REFERENCES}

1. Seferovic PM, Ristic AD, Maksimovic R, Simeunovic DS, Ristic GG, Radovanovic G, et al. Cardiac arrhythmias and conduction disturbances in autoimmune rheumatic diseases. Rheumatology (Oxford) 2006;45:39-42.

2. Knockaert DC. Cardiac involvement in systemic inflammatory diseases. Eur Heart J. 2007;28:1797804.

3. Kahan A, Coghlan G, McLaughlin V. Cardiac complications of systemic sclerosis. Rheumatology (Oxford) 2009;48:45-8

4. Follansbee WP, Miller TR, Curtiss EI, Orie JE, Bernstein RL, Kiernan JM, et al. A controlled clinicopathologic study of myocardial fibrosis in systemic sclerosis (scleroderma). J Rheumatol 1990;17:656-62.

5. Tyndall AJ, Bannert B, Vonk M, Airò P, Cozzi F, Carreira PE, et al. Causes and risk factors for death in systemic sclerosis: a study from the EULAR Scleroderma Trials and Research (EUSTAR) database. Ann Rheum Dis 2010;69:1809-15.

6. Kostis JB, Seibold JR, Turkevich D, Masi AT, Grau RG, Medsger TA Jr, et al. Prognostic importance of cardiac arrhythmias in systemic sclerosis. Am J Med 1988;84:1007-15.

7. Sgreccia A, Morelli S, Ferrante L, Perrone C, De Marzio P, De Vincentiis G, et al. QT interval and QT 
dispersion in systemic sclerosis (scleroderma). J Intern Med 1998;243:127-32.

8. Kors JA, Ritsema van Eck HJ, van Herpen G. The meaning of the Tp-Te interval and its diagnostic value. $\mathrm{J}$ Electrocardiol 2008;41:575-80.

9. Antzelevitch C, Sicouri S, Di Diego JM, Burashnikov A, Viskin S, Shimizu W, et al. Does Tpeak-Tend provide an index of transmural dispersion of repolarization? Heart Rhythm 2007;4:1114-6.

10. Castro Hevia J, Antzelevitch C, Tornés Bárzaga F, Dorantes Sánchez M, Dorticós Balea F, Zayas Molina $\mathrm{R}$, et al. Tpeak-Tend and Tpeak-Tend dispersion as risk factors for ventricular tachycardia/ventricular fibrillation in patients with the Brugada syndrome. $\mathrm{J}$ Am Coll Cardiol 2006;47:1828-34.

11. Smetana P, Schmidt A, Zabel M, Hnatkova K, Franz $\mathrm{M}$, Huber $\mathrm{K}$, et al. Assessment of repolarization heterogeneity for prediction of mortality in cardiovascular disease: peak to the end of the $T$ wave interval and nondipolar repolarization components. J Electrocardiol 2011;44:301-8.

12. Erikssen G, Liestøl K, Gullestad L, Haugaa KH, Bendz B, Amlie JP. The terminal part of the QT interval ( $\mathrm{T}$ peak to $\mathrm{T}$ end): a predictor of mortality after acute myocardial infarction. Ann Noninvasive Electrocardiol 2012;17:85-94.

13. Zhao X, Xie Z, Chu Y, Yang L, Xu W, Yang X, et al. Association between Tp-e/QT ratio and prognosis in patients undergoing primary percutaneous coronary intervention for ST-segment elevation myocardial infarction. Clin Cardiol 2012;35:559-64.

14. Gupta P, Patel C, Patel H, Narayanaswamy S, Malhotra $\mathrm{B}$, Green JT, et al. T(p-e)/QT ratio as an index of arrhythmogenesis. J Electrocardiol 2008;41:567-74.

15. Preliminary criteria for the classification of systemic sclerosis (scleroderma). Subcommittee for scleroderma criteria of the American Rheumatism Association Diagnostic and Therapeutic Criteria Committee. Arthritis Rheum 1980;23:581-90.

16. van den Hoogen F, Khanna D, Fransen J, Johnson SR, Baron M, Tyndall A, et al. 2013 classification criteria for systemic sclerosis: an American College of Rheumatology/European League against Rheumatism collaborative initiative. Arthritis Rheum 2013;65:2737-47.

17. LeRoy EC, Black C, Fleischmajer R, Jablonska S, Krieg T, Medsger TA Jr, et al. Scleroderma (systemic sclerosis): classification, subsets and pathogenesis. J Rheumatol 1988;15:202-5.

18. Ungprasert $\mathrm{P}$, Charoenpong $\mathrm{P}$, Ratanasrimetha $\mathrm{P}$, Thongprayoon C, Cheungpasitporn W, Suksaranjit P. Risk of coronary artery disease in patients with systemic sclerosis: a systematic review and metaanalysis. Clin Rheumatol 2014;33:1099-104.

19. Rodríguez-Reyna TS, Morelos-Guzman M, Hernández-Reyes P, Montero-Duarte K,
Martínez-Reyes C, Reyes-Utrera C, et al. Assessment of myocardial fibrosis and microvascular damage in systemic sclerosis by magnetic resonance imaging and coronary angiotomography. Rheumatology (Oxford) 2015;54:647-54.

20. Seung-Geun L, Young-Eun P, Su-Yeon C, Eun-Kyung P, Geun-Tae K, Ki-Seok C, et al. Systemic sclerosis is not associated with increased coronary artery calcium deposition. Arch Rheumatol 2013;28:242-50.

21. D'Angelo WA, Fries JF, Masi AT, Shulman LE. Pathologic observations in systemic sclerosis (scleroderma). A study of fifty-eight autopsy cases and fifty-eight matched controls. Am J Med 1969;46:428-40.

22. James TN. De subitaneis mortibus. VIII. Coronary arteries and conduction system in scleroderma heart disease. Circulation 1974;50:844-56.

23. Dweck MR, Boon NA, Newby DE. Calcific aortic stenosis: a disease of the valve and the myocardium. $\mathrm{J}$ Am Coll Cardiol 2012;60:1854-63.

24. Nerheim P, Krishnan SC, Olshansky B, Shivkumar K. Apoptosis in the genesis of cardiac rhythm disorders. Cardiol Clin 2001;19:155-63.

25. Ioannidis JP, Vlachoyiannopoulos PG, Haidich AB, Medsger TA Jr, Lucas M, Michet CJ, et al. Mortality in systemic sclerosis: an international meta-analysis of individual patient data. Am J Med 2005;118:2-10.

26. Lubitz SA, Goldbarg SH, Mehta D. Sudden cardiac death in infiltrative cardiomyopathies: sarcoidosis, scleroderma, amyloidosis, hemachromatosis. Prog Cardiovasc Dis 2008;51:58-73.

27. Nordin A, Björnådal L, Larsson A, Svenungsson E, Jensen-Urstad K. Electrocardiography in 110 patients with systemic sclerosis: a cross-sectional comparison with population-based controls. Scand J Rheumatol 2014;43:221-5.

28. Gialafos E, Konstantopoulou P, Voulgari C, Giavri I, Panopoulos S, Vaiopoulos G, et al. Abnormal spatial QRS-T angle, a marker of ventricular repolarisation, predicts serious ventricular arrhythmia in systemic sclerosis. Clin Exp Rheumatol 2012;30:327-31.

29. Kors JA, van Herpen G, van Bemmel JH. QT dispersion as an attribute of T-loop morphology. Circulation 1999;99:1458-63.

30. Yayla Ç, Bilgin M, Akboğa MK, Gayretli Yayla K, Canpolat U, Dinç Asarcikli L, et al. Evaluation of Tp-E Interval and Tp-E/QT Ratio in Patients with Aortic Stenosis. Ann Noninvasive Electrocardiol 2015 Aug 5.

31. Acar G, Yorgun H, Inci MF, Akkoyun M, Bakan B, Nacar AB, et al. Evaluation of Tp-e interval and Tp-e/ QT ratio in patients with ankylosing spondylitis. Mod Rheumatol 2014;24:327-30.

32. Acar GR, Akkoyun M, Nacar AB, Dirnak I, Ylldırım Çetin G, Nur Yıldırım M, et al. Evaluation of Tp-e interval and Tp-e/QT ratio in patients with rheumatoid arthritis. Turk Kardiyol Dern Ars 2014;42:29-34. 